\title{
Princípios de Lean Manufacturing em uma empresa do setor cimenteiro
}

O presente trabalho tem como propósito o estudo das filas de veículos em uma balança rodoviária de uma indústria cimenteira localizada no Estado do Rio de Janeiro, em que através de um estudo de caso, objetiva-se a otimização dos processos desta balança. O objetivo principal é a eliminação destas filas de veículos, estabelecendo um conjunto de atividades essenciais padrão para a boa execução do fluxo de produção e transporte, dentro da capacidade operacional, excluindo o desperdício, a fim de obter um processo otimizado na balança da área interessada. Como ferramentas deste trabalho, foram utilizadas o Estudo de Tempos de Movimentos, como instrumento básico para levantamento das informações e análise do cenário; e tópicos da cultura Lean Thinking, como método de avaliação das atividades essenciais ao processo e as causas de desperdício. Além delas, porém não menos importantes, empregou-se as ferramentas de Brainstorm, Matriz de Decisão e $5 \mathrm{~W} 1 \mathrm{H}$, como levantamento, priorização e gerenciamento dos projetos de melhoria. Os resultados mostraram as principais causas de desperdício, culminando, principalmente, na mudança do modal de transporte e no sequenciamento de atividades. Por fim, conclui-se que as filas de veículos geravam uma interrupção indesejada na execução do fluxo, sendo necessário algumas ações para aumento de produtividade do setor da balança rodoviária.

Palavras-chave: Lean Manufacturing; Logística; Balança rodoviária.

\section{Principles of Lean Manufacturing: a case study in a cement sector industry}

This article is intended the study of the vehicle queuing on a road balance at a cement industry based in Rio de Janeiro, thought this case study, the objective is to optimize the process of this balance. The main goal is the queue elimination, with a group of standard actions to proper implementation of the production and transportation flow, within the operational capacity, excluding waste, in order to obtain an optimized process in the balance.

As tools of this article, it was used the Methods Time Measurement, as basic tools for collecting information and scenario analysis; and topics of Lean Thinking culture as a method of evaluating the activities essential to the process and the waste causes. Furthermore, but not less important, it was used the Brainstorm tool, Pugh Matrix and $5 \mathrm{~W} 1 \mathrm{H}$, as survey, prioritization and management of improvement projects. The results showed the major causes wastage, resulting mainly in the change of modal transportation and activity sequencing. Finally, it is concluded the vehicle queues generated an unwanted interruption in the flow, requiring some actions to improve the productivity of the road balance.

Keywords: Lean Manufacturing; Logistic; Road scale.

\section{Topic: Operações e Processos da Produção}

Reviewed anonymously in the process of blind peer.

\section{Paola de Oliveira Pinto}

Universidade da Região da Campanha, Brasil

http://lattes.cnpq.br/9818466501943842

paolaipp@gmail.com

\section{Ualison Rébula Oliveira}

Universidade Federal Fluminense, Brasil

http://lattes.cnpq.br/6460931837390456

ualison.oliveira@gmail.com
Received: 26/01/2017

Approved: 26/03/2017
Referencing this:

PINTO, O. P.; OLIVEIRA, R. U.. Princípios de Lean Manufacturing em uma empresa do setor cimenteiro. Revista Brasileira de Administração Científica, v.8, n.1, p.300-313, 2017. DOI: http://doi.org/10.6008/SPC2179-684X.2017.001.0022 


\section{INTRODUÇÃO}

Atualmente, as organizações buscam inovação, redução de custos e aumento na produtividade visando competitividade no mercado globalizado. Nesse cenário concorrente, surgiu, no final dos anos 80 , a cultura Lean. Um estudo realizado na época entre as indústrias automobilísticas do mundo inteiro, mostrou que a empresa Toyota apresentava um método diferenciado de gerenciamento de negócios, que envolvia desde o desenvolvimento de produto à manufatura. Como resultado deste estudo, viu-se que este método tem a sua aplicação ampliada para outros tipos de negócios como indústrias de base e serviços (BRANDI et al., 2009).

A cultura Lean visa combater os desperdícios dentro dos processos da organização, visando a otimização dos mesmos, buscando meios para alcançar mais resultados com menos esforços, retirando as atividades que menos agregam valor e aumentando a performance das ações principais (BRANDI et al., 2009). O objeto de estudo desta pesquisa foram as balanças rodoviárias situadas em uma fábrica de cimentos, sendo uma localizada na entrada e outra na saída de veículos. Nos momentos de maior atividade, ambas podem ser utilizadas para o mesmo fim, conforme instrução do supervisor de expedição, que é o responsável pelo gerenciamento das atividades do local. Portanto, em determinados momentos, as duas unidades são utilizadas para entrada ou saída da frota.

Todos os veículos que entram para carregar na fábrica utilizam as balanças, tendo em vista que todos devem ser aferidos por questões de auditoria e para verificação de possíveis desvios. A média diária são de 502 veículos nas balanças da unidade. Sob esse cenário de funcionamento da área expedição e entendendo haver um conjunto de ações que causavam o desperdício de tempo e consequente gargalo de atividades.

Daí, surgiu a necessidade de aprofundar os estudos das atividades, para prospecção de pontos de melhoria para otimização dos processos, sendo necessário verificar possíveis ações que possam ser transferidas para outras áreas, analisar a viabilidade de se automatizar algumas delas, excluir as atividades desnecessárias e analisar o cenário com o aumento do share ferroviário.

Neste contexto, o presente artigo tem como objetivo principal à otimização dos processos da balança, reduzindo o tempo médio de permanência do veículo (inclui-se a própria pesagem e outras atividades). Como proposta secundária, pretende-se analisar o cenário com aumento do share ferroviário, que teve início em 2014 e perdurará até 2016 com aquisição de novos vagões, já que a redução no número de veículos é prevista pela análise de capacidade anteriormente estudada.

Justifica-se a escolha de uma empresa no negócio de cimentos, como foco desta análise, por fazer parte do ramo da construção civil, que está em evidência devido às grandes obras da Copa de 2014 e as Olímpiadas de 2016. Além disso, o ramo da construção civil em 2012, foi responsável por uma receita líquida de $R \$ 312,9$ bilhões, segundo o Portal Brasil. 


\section{REVISÃO TEÓRICA}

\section{Comparação entre os modais Ferroviário e Rodoviário no Brasil}

Cada vez mais, as empresas estão buscando obter vantagem competitiva no mercado, sempre procurando inovar os processos, reduzir os custos e garantir a boa produtividade. Embasado nestes quesitos e tendo a logística como uma área estratégica dentro das companhias, bons resultados serão encontrados pelas empresas (BOLZAN, 2010).

A logística surgiu na Segunda Guerra Mundial, quando os militares verificaram a necessidade de transportar e armazenar alimentos e remédios. Depois disso, o termo passou a ser utilizado nas empresas e hoje é uma das áreas mais estratégicas das corporações, visto que a escolha de um modal errado pode acarretar altos custos, demora na entrega, desgaste com o cliente e queda no nível de serviço (BOLZAN, 2010).

Sendo assim, em 1993, Ballou descreveu a Logística como: "Todas as atividades de movimentação e armazenamento, que facilitam o fluxo de produtos desde o ponto de aquisição da matéria-prima até o ponto de consumo final, assim como os fluxos de informação que colocam os produtos em movimento, com o propósito de providenciar níveis de serviço adequado aos clientes a um custo razoável" (BALLOU, 1993). Dessa forma, o modal a ser utilizado é um dos fatores mais importantes na Logística. Os modais podem ser: rodoviário, ferroviário, aquaviário, marítimo, duto viário e aéreo. O valor agregado do produto, a distância a ser percorrida, a facilidade para contratação e agilidade na entrega, são fatores preponderantes na escolha do modal mais apropriado para cada tipo de carga (ROCHA, 2006).

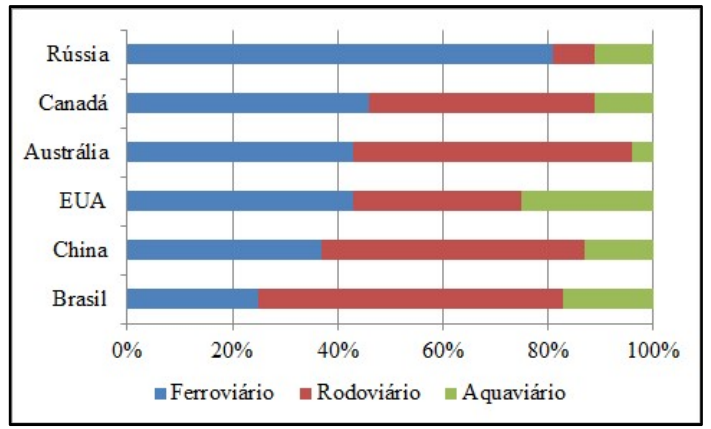

Figura 1: Matriz de transporte de países com grandes dimensões territoriais. Fonte: Pinto Junior (2010).

Produtos com baixo valor agregado, como o cimento, necessitam que o transporte seja eficiente para que ele seja competitivo. Com isso, o aumento na utilização de ferrovias, além de ser mais sustentável relacionado ao modal rodoviário, é excelente para o bom desempenho da organização, pois tem menor custo, utiliza menos mão-de-obra, tem maior capacidade e impacta em menor número de veículos na planta (BOLZAN, 2010).

Infelizmente, no Brasil, esse modal não é muito utilizado, pois a infraestrura é precária e as dificuldades para contratação são enormes. Além disso, não há uma malha ferroviária homogênea, que conecte as regiões de forma eficiente, impactadas pelos diferentes tamanhos das bitolas, o que acarreta no transbordo da carga, fator que onera a operação, fazendo assim, que o modal rodoviário seja mais vantajoso (SILVA, 2011). Fazendo uma comparação com a distribuição de carga entre os modais e levando em 
consideração a dimensão territorial do país, na figura 2, nota-se a discrepância nesta distribuição (PINTO JUNIOR, 2010).

No caso do Brasil, este fato ocorre pelas políticas públicas de investimento do governo, que entre as décadas de 50 e 70 priorizaram a construção de rodovias, devido às instalações de empresas automobilísticas no país. Além disso, segundo Gustavo Bambini, presidente da Associação Nacional de Transporte Ferroviário, o custo para se construir $1 \mathrm{~km}$ de ferrovia é de US\$1,5mi; em contrapartida, o valor para se construir $1 \mathrm{~km}$ de rodovia é de US\$200mil. Outro fator que estimula a falta de investimento em ferrovias é o longo prazo para construção, consumindo mais tempo que os mandatos de atuação do governo, implicando que o compromisso de investimento e execução seja passado de uma gestão para a outra (FRANÇA, 2014).

\section{Tempos e Movimentos}

Hoje nas companhias, a administração do tempo é algo determinante para uma boa produtividade, tendo em vista que ele é um fator inelástico e imutável. O Estudo de Tempos e Movimentos surgiu em 1911 com a publicação do livro de Taylor, 'Princípios de Administração Científica', onde ele lista os 4 princípios, conforme o quadro 1 (CHIAVENATO, 1987).

\section{Quadro 1: Princípios da Administração Científica.}

1. Princípio de planejamento: substituir no trabalho o critério individual do operário, a improvisação e atuação empírico-prática, pelos métodos baseados em procedimentos científicos. Substituir a improvisação pela ciência, através do planejamento do método.

2. Princípio de preparo: selecionar cientificamente os trabalhadores de acordo com suas aptidões e prepará-los para produzirem mais e melhor, de acordo com o método planejado. Além do preparo da mão-de-obra, preparar também as máquinas e equipamentos de produção, bem como o arranjo físico e a disposição racional.

3. Princípio do Controle: controlar o trabalho para se certificar de que está sendo executado de acordo com as normas estabelecidas e segundo o plano previsto. A gerência deve cooperar com os trabalhadores, para que a execução seja a melhor possível.

4. Princípio da execução: distribuir distintamente as atribuições e as responsabilidades para que a execução seja bem mais disciplinada.

Fonte: Chiavenato (1987).

De acordo com Chiavenato (1987), Taylor "verificou que o trabalho pode ser executado melhor e mais economicamente através da análise do trabalho, isto é, da divisão e subdivisão de todos os movimentos necessários à execução de cada operação de uma tarefa" (CHIAVENATO, 1987). Mapeando todo o processo e dividindo todas as atividades, simplifica-se a identificação de quais ações serão descartáveis, otimizadas ou automatizadas, reduzindo assim, o desperdício do tempo de trabalho (OLÍVIO, 2002).

Conhecidos como Pais do Estudo dos Movimentos, Frank e Lilian Gilberth, trabalharam com Taylor com intuito de aumentar a produtividade pelo esforço humano (OLíVIO, 2002). Barnes (1963) lista alguns trabalhos realizados pelo casal Gilberth, dentre eles: "invenções e melhorias de valor na construção civil, estudos sobre a fadiga, monotonia, transferência de habilidades entre operários, trabalhos para os desabilitados e o desenvolvimento de técnicas como o gráfico de fluxo de processo, estudo de micro movimentos e o cronociclógrafo". 
O objetivo do estudo era descobrir a melhor forma de se executar uma atividade depois de se analisar todo o processo que ela está envolvida (BARNES, 1963). Algumas críticas à Administração Científica surgiram, como por exemplo: padronização de trabalho altamente divididos, baixa motivação do pessoal e alienação do trabalho. No entanto, hoje há uma tendência de reavivamento do Estudo de Taylor. Segundo Peter Drucker,

Hoje em dia, é moda menosprezar Taylor e desacreditar sua psicologia antiquada, mas Taylor foi o primeiro homem da história a não aceitar o trabalho como favas contadas, examinando-o e estudando a fundo. A maneira como encarou o trabalho continua a ser o alicerce básico desse estudo. E embora no seu modo de ver o trabalhador tenha sido inquestionavelmente um homem do século XIX, Taylor partiu de objetivos sociais e não da técnica ou do lucro. O que levou Taylor ao seu trabalho e sempre motivou foi, em primeiro lugar, o desejo de libertar o trabalhador do fardo do trabalho excessivo, que destrói tanto o corpo como a alma. Depois, foi sua esperança de possibilitar a colocação de uma vida digna ao alcance do trabalhador, por meio de sua maior produtividade no serviço. (DRUCKER, 1984)

Tendo como plano de fundo a tratativa de divisão do trabalho e tempo proposta por Taylor, foi desenvolvido o Methods-Time-Measurement (MTM), que consiste em um método de tempos prédeterminados, embasado em estudos de tempos e movimentos, visando a melhoria em operações que implicam em operações manuais que necessitam de ritmo, métodos determinados, ferramentas e equipamentos, para configuração específica de uma área ou setor (RIBEIRO JÚNIOR, 2012).

De acordo com Maynard, o MTM pode ser utilizado nos mais variados casos, como Maynard (1970): Desenvolvimento de Métodos Eficientes antes de iniciar a execução; Melhoria de Métodos Existentes; Estabelecimento dos Tempos padrões; Desenvolvimento de fórmulas de tempo para dados prédeterminados; Estimativas de custos; Orientação do projeto ao produto; Desenvolvimento de projetos de ferramentas eficientes; Seleção de equipamento eficiente; Treinamento de supervisores para implantar a consciência de métodos; Estabelecimento de estudo de tempos e fixação dos salários; Treinamento do operador; e Pesquisas em matérias como métodos de operação, treinamento e avaliação do ritmo.

Além disso, os benefícios do MTM são vistos na otimização dos processos, redução de custos, compra de máquinas adequadas, melhor ergonomia nas atividades e no estabelecimento da melhor forma de se desenvolver uma atividade. Dessa forma, hoje o MTM está difundido em todo o mundo através de suas associações. Nota-se que é uma ótima ferramenta de gestão para otimização do tempo e melhoria no processo, completando-se com os conceitos de “Mentalidade Enxuta” (OLÍVIO, 2002).

\section{Lean Thinking}

A filosofia Lean surgiu no Japão da década de 80, aparecendo como um novo modelo de gestão da produção, desenvolvido através de um projeto feito pela Toyota, no qual visava combater os desperdícios e reduzir custos. O termo, traduzido como "mentalidade enxuta", logo se tornou uma importante prática de gestão competitiva da produção. Apesar ter sido criado para a indústria automobilística, a técnica pode ser utilizada em todos os outros setores (ROCHA, 2004; FREITAS et al., 2014).

O Lean caracteriza-se pela ideia de obter mais resultados com menos recursos (fazer mais com menos), de forma a satisfazer as necessidades dos clientes. Deste modo, os resultados alcançados são: 
satisfação do cliente com relação a prazo de entrega e custo, redução do lead time das atividades, aumento na qualidade do serviço ou produto e, consequentemente, ganho em lucratividade (WOMACK et al., 2003). De acordo com o Womack et al. (2003), existem 5 princípios da Mentalidade Enxuta a serem seguidos. Portanto, com a utilização dos princípios da filosofia Lean, os principais objetivos alcançados serão a redução dos desperdícios, o aumento na produtividade e o ganho de lucratividade.

Valor: Primeiramente, deve-se identificar o que é Valor. Um fato interessante neste item é que quem o define é o cliente, pois a necessidade dele é que gera valor. Dessa forma, cabe à empresa sanar essa necessidade e cobrar o que ela julga justo para se manter no negócio e aumentar a rentabilidade, sempre buscando redução de custos, melhorias nos processos e ganhos nos índices de qualidade (PICCHI, 2001);

Fluxo de Valor: Posteriormente, necessita-se localizar o Fluxo de Valor. Este será feito através de um mapeamento do processo das atividades, separando-as em 3 tipos distintos (WOMACK et al., 2003): as atividades que geram valor; as atividades que não geram valor, mas são necessárias para o processo; as atividades que não geram valor e devem ser eliminadas;

Fluxo Contínuo: Após a execução dos dois primeiros princípios, deve-se dar continuidade ao restante dos processos e atividades, implicando na alteração da cultura e filosofia de pensamento das pessoas, buscando sempre a melhor forma de executar cada tarefa, inovando nas ideias e adquirindo novos conhecimentos. Como conclusão deste processo, obtém-se redução do tempo das atividades restantes, atendendo os clientes de forma rápida e eficiente, dando a sensação de priorização de suas solicitações (WOMACK et al., 2003);

Produção Puxada: as empresas evitam os estoques de produtos e o desperdício que ele possa trazer, tanto em custo quanto em produtividade. O processo passa a ocorrer através de uma demanda pré-determinada, em que a cliente dita à quantidade e o tempo de necessidade do produto, evitando o armazenamento (PICCHI, 2001);

Perfeição: O último passo deve ser o objetivo de todas as áreas envolvidas que culminam na atividade final da organização. A perfeição deve ser aprimorada em todas as etapas do processo, em que a parte tenha conhecimento do todo, para que as ações possam refletir de maneira positiva em todas as outras, contribuindo para a melhoria de forma geral (PICCHI, 2001).

\section{METODOLOGIA}

O método de pesquisa, primeiramente, envolveu a realização de um workshop (brainstorm) nos dias 30/10/2014, 03/11/2014 e 04/11/2014, com todos os envolvidos no processo (técnicos de expedição, supervisor de expedição e coordenador de logística) para levantamento das atividades que poderiam ser automatizadas, excluídas ou transferidas da balança. Posteriormente, analisou-se o impacto do aumento do share ferroviário nas transferências para os centros de distribuição $(C D)$, levando-se em consideração o incremento no número de vagões que serão adquiridos no período de 2014 a 2016.

Uma Matriz de Decisão das ideias foi utilizada, visando como fatores principais a agilidade na implementação do projeto, baixo investimento envolvido e a quantificação da redução de tempo no processo. Após a escolha das ações que seriam implantadas, foi utilizada a ferramenta gerencial $5 \mathrm{~W} 1 \mathrm{H}$ para dar andamento e prazo às atividades. Com o cenário descrito, provisionou-se um aumento da capacidade operacional da balança, fim das filas de caminhões, organização do pátio, satisfação dos motoristas e melhora no clima de trabalho. 


\section{RESULTADOS}

\section{Coleta de Informações}

A Empresa envolvida na pesquisa atua no ramo siderúrgico e na indústria cimenteira, visto como uma oportunidade de negócio, considerando-se que o resíduo de beneficiamento de ferro pode ser aproveitado na produção de cimento. A referida empresa está localizada no Estado do Rio de Janeiro e, a partir de 2015, conta com uma nova unidade em Minas Gerais, devido ao aumento nas vendas (atingindo 1,8 milhão de toneladas de cimento).

Além das indústrias de transformação, a cimenteira possui Centros de Distribuição (CD) localizados nos estados de Rio de Janeiro, São Paulo e Minas Gerais. Nos dias de hoje, a empresa produz cimento em granel e ensacado. Em ambos os casos, os produtos juntamente com o veículo devem ser pesados na balança rodoviária, objeto de estudo dessa pesquisa.

O produto pode ser vendido nas seguintes formas: CIF (Cost Insurance Freight), onde o frete rodoviário é por conta da empresa que está vendendo o produto; FOB (Free On Board), onde o frete rodoviário é por conta da empresa que está comprando o produto; e Transferências para $C D$, onde a organização transfere o produto para abastecer $\mathrm{O} C D$, a maior parte nesse caso é feito pelo modal ferroviário, mas pode ocorrer transferências via rodovia.

Para o início desse projeto, foi solicitado um Estudo de Tempos e Movimentos nas atividades dos técnicos de expedição da balança rodoviária, localizada na fábrica de cimentos. O objetivo inicial era verificar se, na alocação das atividades dos recursos, havia tempo disponível para inclusão de uma operação no processo. Na época, a intenção dos gestores era de incluir a atividade de emissão de pedágio, visto que hoje esse serviço é feito pelas transportadoras contratadas e o cenário ideal seria que um funcionário próprio o fizesse.

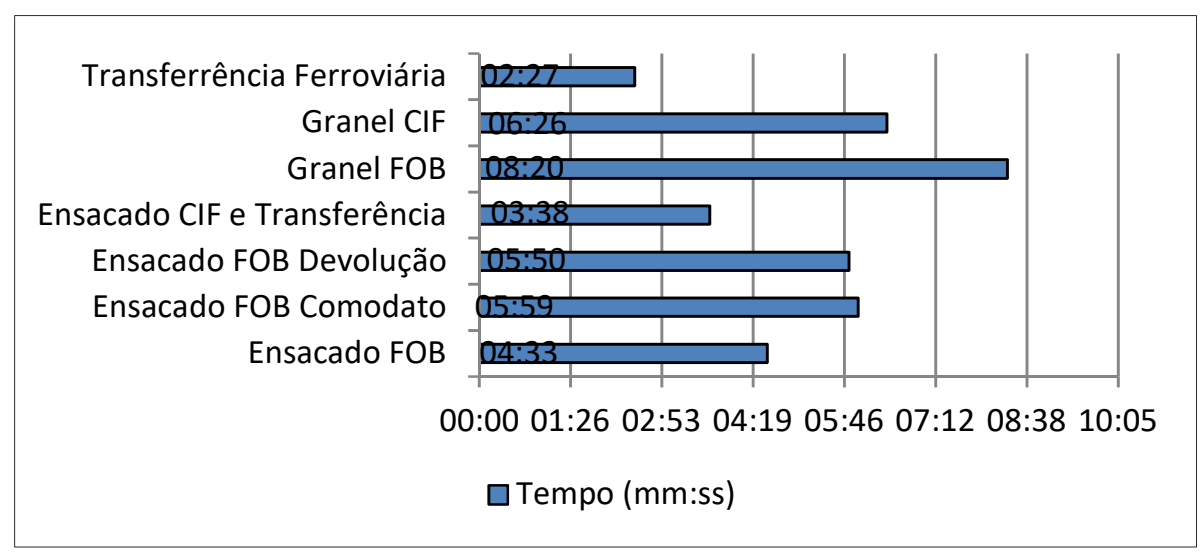

Figura 2: Tempo em minutos por atividade.

Com o tempo médio de cada atividade definido e, considerando a proporcionalidade entre elas, obteve-se a média ponderada de 04:48 (288 segundos) por evento, chamada de Processo Core Business. Além disso, para o estudo de tempos e movimentos, considerou-se os acréscimos de 37 segundos por evento devido à indisponibilidade para troca de turno, refeição e limpeza da sala e 19 segundos por evento para 
Outras Atividades (retrabalho do documento de transporte, estorno de nota fiscal emitida erroneamente, pedido de manobra de vagão e etc.).

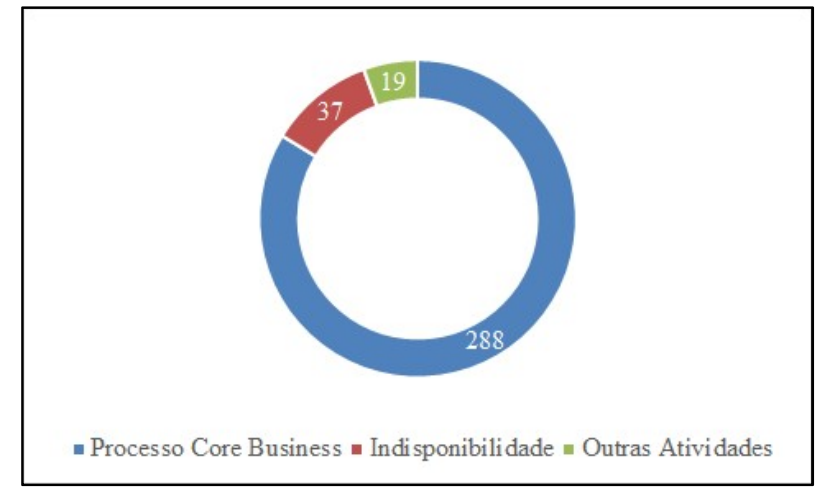

Figura 3: Tempo médio total Processo em segundos.

Portanto, considerando toda a análise do processo, o tempo total para a realização de todas as atividades do processo foi de 344 segundos, ou seja, 05:44 minutos. Considerando-se a existência de dois funcionários na balança e que o processo é feito em 05:44, afirma-se que em 1 hora é possível atender 20 veículos.

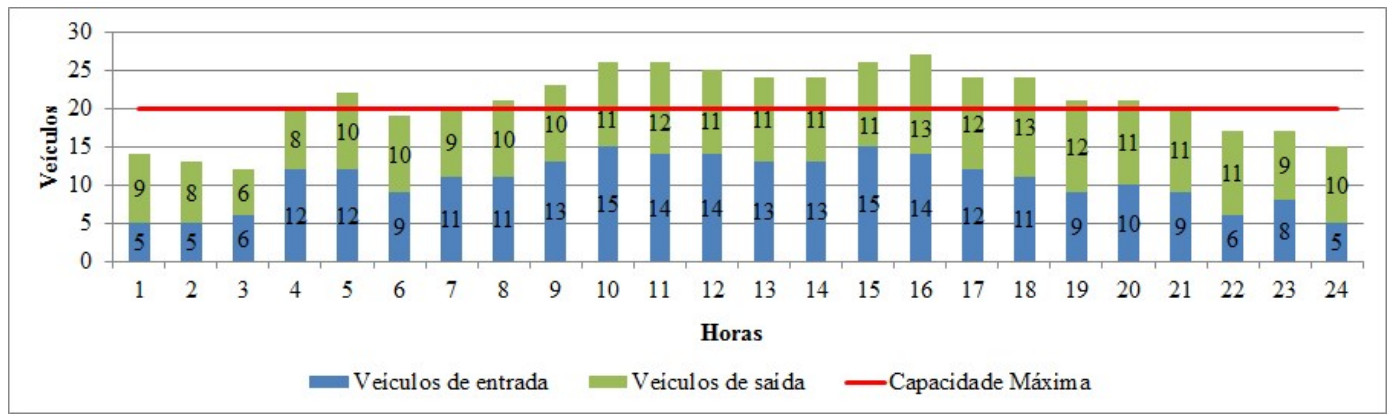

Figura 4: Média diária por hora de (janeiro à junho de 2014).

$\mathrm{Na}$ figura 4 verifica-se que, das $05 \mathrm{~h}$ até as $20 \mathrm{~h}$ (com exceção das 10:00 horas) as balanças trabalham acima de sua capacidade, ou seja, 14h/dia ela funciona de forma ineficiente. Além disso, verifica-se que às 16h é o horário com maior movimentação de veículos. À princípio, verificou-se que o lead time para realização da rotina da balança era insuficiente para execução de todas as atividades. Com isso, prova-se estatisticamente o que ocorre na realidade: geração de filas dentro da fábrica e caminhoneiros estressados.

\section{Resultado da análise dessas informações}

Tendo como plano de fundo o estudo de Tempos e Movimentos que levou à contextualização do tempo total do processo na balança, e com o intuito de levantar oportunidades de otimização dos tempos de execução das atividades, realizou-se um Brainstorm como descrito acima (na seção "Introdução") com os envolvidos no processo. Como resultado desta reunião, surgiram 18 (dezoito) ideias, sendo 6 (seis) relacionadas à Tecnologia da Informação, 1 (uma) relacionada à logística, 5 (cinco) relacionada à infraestrutura e 6 (seis) relacionada à reengenharia de processo. No quadro 2 seguem as ideias ligadas em cada uma das áreas mencionadas. 
Quadro 2: Ideias originadas do Brainstorm.

\begin{tabular}{|l|}
\hline Tecnologia da Informação \\
\hline Colocar uma impressora para cada Técnico de Expedição \\
\hline Colocar uma TV com os pedidos na tela (caso programação na balança) \\
\hline Colocar as informações dos carimbos automáticos no SAP \\
\hline Ajustar na planilha de entrada \\
\hline Exigir que as transportadoras Estapostes e TVL recebam NF automática por e-mail \\
\hline Conectar a balança no SAP e instalar um sistema de código de barras para captação do Documento de Transporte \\
\hline Logística \\
\hline Aumentar share ferroviário \\
\hline Reengenharia de processo \\
\hline Transferir comodato para Técnico fora da balança \\
\hline Transferir programação de trem para Técnico fora da balança \\
\hline Transferir programação FOB para Técnico fora da balança \\
\hline Transferir atendimento à comercial e à logística para Técnico fora da balança \\
\hline Disponibilizar o lacre granel com o Operador de Granel (evitar desvio de lacre) \\
\hline Comercial fazer a programação e o Documento de Transporte - FOB \\
\hline Infraestrutura \\
\hline Colocar um guichê com alto faltante \\
\hline Layout - Sinalizar pátio e criar regra para estacionamento \\
\hline Colocar um medidor de vazão na tromba de carregamento com ticket - granel \\
\hline Criar um processo de fiscalização fora da balança (Portaria) \\
\hline Não pesar ensacado \\
\hline
\end{tabular}

De todas as 18 (dezoito) ideias levantadas, verificou-se que 2 (duas) delas tinham inviabilidade pelo gestor da área, sendo elas: Disponibilizar o lacre granel com o Operador de Granel (evitar desvio de lacre) sob a justificativa de que a caligrafia poderia ser interpretada errada, gerando transtornos na emissão de NF; e Colocar um guichê com alto-falante sob a justificativa de que não simplificaria a audição.

Com esta lista de oportunidades, elaborou-se uma Matriz de Decisão, ferramenta utilizada para priorização, considerando fatores que mais possam impactar na execução dos projetos, entendendo a necessidade e condição econômica da companhia, atribuindo-se uma importância relativa a cada um destes fatores. Neste caso, os itens foram priorizados conforme a agilidade na implementação do projeto, o baixo investimento e a quantificação da redução de tempo no processo. Cada um desses itens recebeu um peso, respectivamente de 5,10 e 5 .

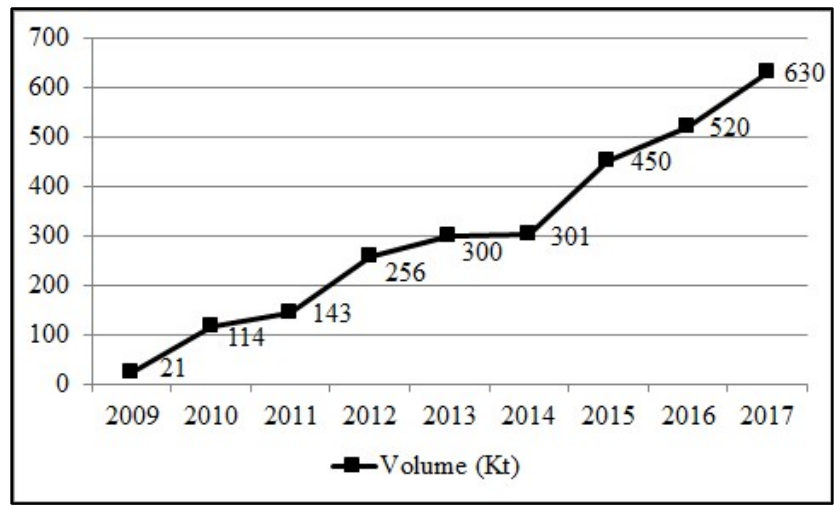

Figura 5: Escoamento Ferroviário.

Além disso, a matriz considerou a relação esforço versus impacto para a realização dos projetos relacionados às oportunidades levantadas. Outro fator importante considerado no estudo, foi o aumento do uso do transporte ferroviário para as transferências para os CDs. Como resultado do grande investimento na compra de novos vagões, a projeção é de que até 2017 haja um escoamento de 630kt. Com o aumento de 
escoamento via modal ferroviário, pretende-se reduzir o volume de veículos rodoviários na balança, que implica em maior fluidez do processo, contribuindo para que a área não seja mais um gargalo na operação.

\section{DISCUSSÃO}

Tendo em vista as análises feitas anteriormente, concluiu-se que o tempo de processo da balança deveria ser reduzido. Para isso, mensurou-se o tempo necessário para que não houvessem mais gargalos. 0 primeiro ponto analisado foi o impacto que o incremento ferroviário, realizado de 2014 a 2016, trouxe para o fluxo de veículos na balança. Para isso, utilizaram-se as seguidas premissas: a carga de 1 vagão representa 2,56 veículos; e 1 vagão faz 6 ciclos por mês. Tendo como base essas premissas, conclui-se que em um mês haverá a redução de aproximadamente 15 (quinze) veículos na balança. Considerando que em 2016 o cenário envolve o total de 65 vagões adquiridos para a função, com disponibilidade de 95\%, pretende-se uma redução mensal de 945 veículos, implicando em um decréscimo diário de 31 veículos na balança, como pode ser constatado na tabela 1.

Tabela 1: Incremento de vagão.

\begin{tabular}{|c|c|c|c|c|}
\hline Ano & Quantidade Vagão & Disponibilidade & Veículos reduzidos/mês & Veículos reduzidos/dia \\
\hline 2014 & 26 & $95 \%$ & 378 & 13 \\
\hline 2015 & 42 & $95 \%$ & 610 & 20 \\
\hline 2016 & 65 & $95 \%$ & 945 & 31 \\
\hline
\end{tabular}

Portanto, considerando a redução de veículos devido ao incremento do modal ferroviário e se fazendo uma projeção diária da quantidade de frota, tem-se que a quantidade no período de maior movimentação será de 25 veículos em 2016, ao invés de 27 considerado anteriormente, conforme mostrado na tabela 2.

Tabela 2: Distribuição média horária dos véiculos na balança.

\begin{tabular}{|c|c|c|c|c|}
\hline $\begin{array}{l}\text { Hora } \\
\text { do Dia }\end{array}$ & $\begin{array}{c}\text { Total Evento } \\
\text { Atual na balança }\end{array}$ & $\begin{array}{c}\text { Total de Evento } \\
\text { em } 2016 \\
\end{array}$ & $\begin{array}{c}\text { Capacidade } \\
\text { Atual }\end{array}$ & $\begin{array}{c}\text { Capacidade } \\
\text { em } 2016 \\
\end{array}$ \\
\hline $0: 00$ & 15 & 14 & 20 & 26 \\
\hline $1: 00$ & 14 & 13 & 20 & 26 \\
\hline $2: 00$ & 14 & 13 & 20 & 26 \\
\hline $3: 00$ & 13 & 12 & 20 & 26 \\
\hline $4: 00$ & 19 & 18 & 20 & 26 \\
\hline 5:00 & 22 & 21 & 20 & 26 \\
\hline $6: 00$ & 19 & 18 & 20 & 26 \\
\hline 7:00 & 20 & 18 & 20 & 26 \\
\hline $8: 00$ & 21 & 20 & 20 & 26 \\
\hline $9: 00$ & 23 & 22 & 20 & 26 \\
\hline $10: 00$ & 26 & 25 & 20 & 26 \\
\hline $11: 00$ & 26 & 24 & 20 & 26 \\
\hline $12: 00$ & 26 & 24 & 20 & 26 \\
\hline $13: 00$ & 24 & 22 & 20 & 26 \\
\hline $14: 00$ & 24 & 22 & 20 & 26 \\
\hline $15: 00$ & 26 & 24 & 20 & 26 \\
\hline $16: 00$ & 27 & 25 & 20 & 26 \\
\hline $17: 00$ & 24 & 23 & 20 & 26 \\
\hline $18: 00$ & 24 & 23 & 20 & 26 \\
\hline 19:00 & 22 & 20 & 20 & 26 \\
\hline 20:00 & 21 & 20 & 20 & 26 \\
\hline $21: 00$ & 20 & 19 & 20 & 26 \\
\hline 22:00 & 17 & 16 & 20 & 26 \\
\hline 23:00 & 16 & 15 & 20 & 26 \\
\hline Total & 502 & 470 & 480 & 624 \\
\hline
\end{tabular}


Conhecendo o impacto trazido pelo transporte ferroviário no fluxo da balança, verificou-se a redução de tempo necessário para que não ocorram mais gargalos. Considera-se que hoje há uma capacidade de 20 veículos/hora e que o processo de um veículo é de 344 segundos. Aplicando a redução trazida pela diminuição da frota, levando-se em conta que em 2016 a maior movimentação envolve 25 veículos, tem-se como resultado um processo de 275 segundos. Ou seja, será necessário reduzir $20 \%$ do tempo do processo atual (69 segundos) para que não ocorra mais gargalos. Para se alcançar a redução desejada, foi utilizado como método a Matriz de Decisão.

As propostas coletadas no Brainstorm foram elencadas na Matriz de Decisão para devida classificação: Pontuação em relação ao fator Redução do Tempo: Forte correlação: 10, 9 ou 8; Média correlação: 7, 6, 5 ou 4; Baixa correlação: 3, 2 ou 1; Não há correlação: 0. Quanto ao Índice de Importância dos fatores: Tempo de Implantação: Peso 5; Grau de Investimento: Peso 10; Impacto na Reduçãõ do Tempo: Peso 5. Além disso, levou-se em consideração o esforço (alto ou baixo) para aplicação de cada proposta, conforme pode-se ver na tabela 3.

Tabela 3: Matriz de Decisão.

\begin{tabular}{|c|c|c|c|c|c|c|}
\hline \multicolumn{3}{|c|}{ 10-9-8: Forte Correlação } & \multicolumn{2}{|c|}{$\begin{array}{l}\text { 7-6-5-4: Média } \\
\text { Correlação }\end{array}$} & \multirow{3}{*}{$\begin{array}{c}\begin{array}{c}\text { 3-2-1: Baixa } \\
\text { Correlação }\end{array} \\
\text { Total }\end{array}$} & \multirow{3}{*}{$\begin{array}{c}\begin{array}{c}\text { 0: Não há } \\
\text { Correlação }\end{array} \\
\text { Esforço }\end{array}$} \\
\hline & Índice de Importância & 5 & 10 & 5 & & \\
\hline & Ideias & Implantação & Investimento & $\begin{array}{l}\text { Redução do } \\
\text { Tempo }\end{array}$ & & \\
\hline $\mathbf{x 1}$ & $\begin{array}{l}\text { Retirar atendimento à comercial e } \\
\text { logística }\end{array}$ & 10 & 10 & 4 & 170 & Alto \\
\hline $\mathbf{X 2}$ & Retirar comodato da balança & 10 & 10 & 9 & 195 & Alto \\
\hline $\mathbf{X 3}$ & Programação de Trem & 7 & 10 & 7 & 170 & Alto \\
\hline $\mathrm{X4}$ & Fazer programação e DT para FOB & 10 & 10 & 10 & 200 & Alto \\
\hline X5 & $\begin{array}{c}\text { Colocar um medidor de vasão na } \\
\text { tromba de carregamento granel com } \\
\text { ticket }\end{array}$ & 10 & 10 & 9 & 195 & Alto \\
\hline $\mathrm{x} 6$ & $\begin{array}{c}\text { Retirar a fiscalização da balança } \\
\text { (Portaria) }\end{array}$ & 10 & 10 & 6 & 180 & Alto \\
\hline X7 & Não pesar encasado & 10 & 10 & 7 & 185 & Alto \\
\hline$x 8$ & $\begin{array}{c}\text { Diminuir volume de veículo } \\
\text { (Aumentar Share ferroviário) }\end{array}$ & 7 & 5 & 10 & 135 & Baixo \\
\hline X9 & $\begin{array}{l}\text { Conectar a balança no SAP e instalar } \\
\text { um sistema de código de barra para } \\
\text { captação do DT }\end{array}$ & 6 & 6 & 9 & 135 & Alto \\
\hline $\mathbf{X 1 0}$ & $\begin{array}{c}\text { Colocar campos automáticos na } \\
\text { planilha }\end{array}$ & 2 & 0 & 3 & 25 & Baixo \\
\hline $\mathrm{x} 11$ & $\begin{array}{c}\text { Estapostes e TVL receberem NF } \\
\text { automáticas por e-mail }\end{array}$ & 2 & 2 & 2 & 40 & Baixo \\
\hline $\mathrm{X} 12$ & $\begin{array}{c}\text { Colocar as informações do carimbo } \\
\text { automática no SAP }\end{array}$ & 3 & 1 & 2 & 35 & Baixo \\
\hline $\mathrm{x} 13$ & $\begin{array}{l}\text { Comercial fazer programação e DT } \\
\text { para FOB }\end{array}$ & 6 & 0 & 9 & 75 & Alto \\
\hline $\mathrm{X} 14$ & $\begin{array}{l}\text { Colocar uma impressora para cada } \\
\text { técnico de expedição }\end{array}$ & 10 & 10 & 3 & 165 & Alto \\
\hline X15 & $\begin{array}{c}\text { Colocar uma TV com a programação } \\
\text { na Tela }\end{array}$ & 7 & 5 & 4 & 105 & Baixo \\
\hline $\mathrm{X16}$ & Layout - sinalizar pátio & 6 & 5 & 5 & 105 & Baixo \\
\hline
\end{tabular}

Tabela 4: Matriz Esforço versus Impacto.

\begin{tabular}{|l|l|l|c|}
\hline \multirow{2}{*}{ Esforço } & Alto & \multicolumn{1}{|c|}{$\mathrm{X} 1, \mathrm{X} 2, \mathrm{X} 3, \mathrm{X} 4, \mathrm{X} 5, \mathrm{X} 6, \mathrm{X} 7, \mathrm{X} 9, \mathrm{X} 14$} & $\mathrm{X} 13$ \\
\cline { 2 - 4 } & Baixo & \multicolumn{1}{|c|}{ X10, X11, X12 } \\
\hline
\end{tabular}


As propostas contidas no quadrante superior esquerdo eram caracterizadas por necessitar de maior esforço na execução e apresentar maior impacto nos resultados. No entanto, mostraram-se como ações que requerem mais investimento em contratação de mão-de-obra e em infraestrutura, ou seja, de difícil realização. Já a proposta do quadrante superior direito, requeria um alto esforço para implantação, pois seria necessário envolver outra gerência, trazendo um baixo impacto para redução do tempo.

A proposta do quadrante inferior esquerdo, foi a atividade que traria para a área um alto impacto na redução do tempo e com baixo esforço, uma vez que estava alinhada às outras ações já consideradas pela companhia (compra de vagões). As propostas do quadrante inferior direito mostraram-se de fácil implantação e que resultariam um baixo impacto no tempo.

Dessa forma, com um estudo de tempos para cada item, considerando-se a soma dos resultados das propostas do quadrante inferior, obteve-se a redução de 67 segundos por processo, uma diminuição próxima da estimada para que não houvesse mais filas. Para concretização na implantação dos itens, foi utilizado a ferramenta gerencial $5 \mathrm{~W} 1 \mathrm{H}$. Sendo assim, listou-se cada item mostrando o responsável por cada ação (Quem), o local de aplicação (Onde), a necessidade (Por que) e como a proposta seria executada (Como), conforme mostrado na quadro 3.

Quadro 3: Análise 5W1H.

\begin{tabular}{|c|c|c|c|c|c|}
\hline Item & O que (What) & $\begin{array}{c}\text { Quem } \\
(W h o)\end{array}$ & $\begin{array}{c}\text { Quando } \\
(\text { When })\end{array}$ & Por que (Why) & Como (How) \\
\hline 1 & Aumentar "share" Ferroviário & Rômulo & Até 2016 & Diminuirá o no de veículo & Comprando Vagão \\
\hline 2 & $\begin{array}{c}\text { Colocar campos automáticos na } \\
\text { planilha de movimentação }\end{array}$ & Paola & $26 / 11 / 2014$ & $\begin{array}{c}\text { Agilizará o preenchimento da } \\
\text { planilha }\end{array}$ & $\begin{array}{c}\text { Automatizando campos } \\
\text { na planilha }\end{array}$ \\
\hline 3 & $\begin{array}{c}\text { Estapostes e TVL receberem NF } \\
\text { automática }\end{array}$ & Juliana & $30 / 12 / 2014$ & Reduzirá paradas na balança & Ajustando sistema \\
\hline 4 & $\begin{array}{c}\text { Colocar informações de carimbo } \\
\text { automáticos no SAP }\end{array}$ & Juliana & $30 / 12 / 2014$ & $\begin{array}{c}\text { Evitará repetições } \\
\text { desnecessárias }\end{array}$ & Ajustando sistema \\
\hline
\end{tabular}

A implantação destas ações implica em redução do tempo do processo nas atividades da balança, a fim de que não ocorram mais filas. $\mathrm{O}$ aumento de share ferroviário impacta na redução do número diário de veículos, além da simplificação dos processos da balança, que aumentará a capacidade operacional por hora. Desta forma, espera-se que não haja mais gargalo na operação, conforme visto na figura 7.

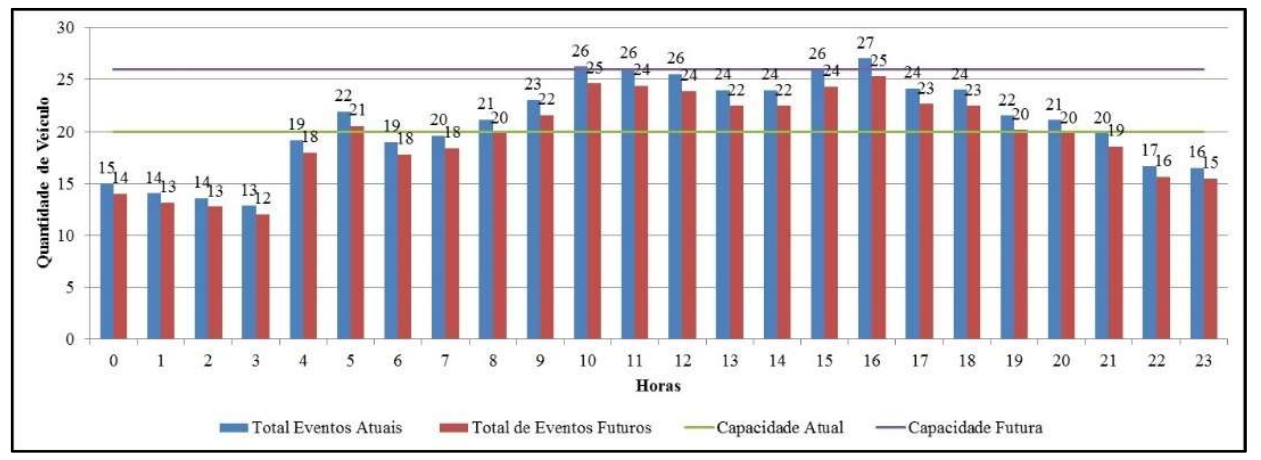

Figura 6: Média diária por hora Atual versus Média Projetada futura.

\section{CONCLUSÕES}

Nos dias atuais, com o fim das barreiras protecionistas, visando manter uma organização competitiva no mercado mundial, faz-se necessário a melhoria contínua nos processos. Mudanças simples podem 
ocasionar ganhos com reais valores para as organizações. Conclui-se que, o Estudo de Tempos e Movimentos e a aplicação da Cultura Lean, são ferramentas úteis aos gestores, uma vez que elas possibilitam a identificação de pontos de gargalo nas operações, como pode ser verificado em relação às filas de veículos e o excesso que atividades que geravam desperdício na balança rodoviária, resultando nas 14 horas diárias de trabalho além da capacidade. Em geral, estas constatações resultam em metas e planos de melhorias que implicam em ganho de produção como o levantamento das 18 ideias que implicavam no aumento da produtividade da área.

O estudo possibilitou a verificação de que a operação geral na balança era um gargalo na fábrica estudada, gerando filas de veículos e propôs a solução de que ajustando-se o sistema, os investimentos, as planilhas de controle e os comportamentos dos envolvidos, seria possível ganhar uma produtividade melhor.

O estudo possibilitou a verificação de que a operação geral na balança era um gargalo na fábrica estudada, gerando filas de veículos e propôs a solução para diminuição do volume de veículos, com o aumento do share ferroviário, alinhado à estratégia da empresa, já que o investimento na aquisição de novos vagões já havia ocorrido. $O$ projeto ainda possibilitou uma a otimização da proposta final frente às análises estudadas e executadas.

Por fim, o trabalho atingiu o objetivo proposto de otimização da operação na balança, culminando na eliminação da fila de veículos, uma vez que diminui em $20 \%$ o tempo de processo (de 344 para 275 segundos), reduzindo a frota na área estudada. $O$ trabalho futuro sugerido, após a implantação de todas as ações, implica em uma nova medição no tempo para constatação dos ganhos reais alcançados, além de propor um treinamento de Cultura Lean a todos envolvidos no processo, para que sejam capazes de enxergar pontos de desperdício, buscando melhoria contínua e agilidade na operação, além de estudar a viabilização das ideias já levantadas e avaliadas na Matriz de Decisão, implicando em uma melhoria contínua do processo.

\section{REFERÊNCIAS}

BALLOU, R. H.. Logística Empresarial: transportes, administração de materiais, distribuição física. São Paulo: Editora Atlas, 1993.

BARNES, R. M.. Estudo de movimentos e de tempo: projeto e medida do trabalho. 6 ed. São Paulo: Editora Edgard Blücher Ltda, 1963.

BOLZAN, E.. Modal Ferroviário: Custo do Transporte de Cimento: Um estudo mercadológico voltado à otimização de recursos, maior eficácia e sustentabilidade da preservação ambiental. Dissertação (Mestrado) - Universidade Cândido Mendes, Niterói, 2010.

BRANDI, D.; CEGLIO, W. E.; SILVA, I. B.; LIMA JÚNIOR, O. F.; OLIVEIRA, T. H.. Aumento de Produtividade e redução do custo operacional em uma empresa de autopeças utilizando conceitos Lean. In: SIMPÓSIO DE EXCELÊNCIA EM GESTÃO E TECNOLOGIA, 9. Anais. Rio de Janeiro: 2012.

CHIAVENATO, I.. Teoria geral da administração: abordagens prescritivas e normativas da administração. São Paulo:

McGraw-Hill, 1987.
DRUCKER, P. F.. Introdução à Administração. São Paulo: Pioneira, 1984.

FRANÇA, V.. Malha ferroviária produtiva do Brasil é a mesma do Império. São Paulo: Estadão, 2014.

FREITAS, W. R. S.; JABBOUR, C. J. C.; TEIXEIRA, A. A.; JABBOUR, A. B. L. S.. Gestão de recursos humanos e manufatura enxuta: evidências empíricas do setor automotivo brasileiro. Revista Produção, Paranaíba, v.24, n.2, p.451-461, 2014.

MAYNARD, H. B.. Manual de Engenharia de Produção: Seção 5: Padrões de Tempos Elementares Pré-determinados. São Paulo: Editora Edgard Blücher, 1970.

OLÍVIO, N. S. M.. MTM como ferramenta para redução de custos: o taylorismo aplicado com sucesso nas empresas de hoje. Revista Produção, Florianópolis, v.2, n.2, 2002.

PICCHI, F.. Lean thinking (mentalidade enxuta) aplicada à construção. In: SIMPÓSIO BRASILEIRO DE GESTÃO DA QUALIDADE, 2. Anais. Fortaleza: Editoração Eletrônica Nordeste, 2001. 
PINTO JÚNIOR, H. Q.. Perspectivas do investimento em Infraestrutura. Rio de Janeiro: UFRJ, 2010.

RIBEIRO JÚNIOR, L. C. A.; CHAVES, C. A.. Análise de posto de trabalho com aplicação do MTM como ferramenta para padronização de tempo. Revista Exacta, São Paulo, v.10, n.2, p.167-179, 2012.

ROCHA, E. A.. Comparação entre os modais ferroviários e rodoviários no transporte de soja, da região Centro-Oeste ao porto de Santos. Monografia (Graduação em Tecnologia em Logística com ênfase em transporte) - Faculdade de Tecnologia da Zona Leste, São Paulo, 2006.
ROCHA, F. E. M.. Logística e lógica na construção lean. Fortaleza: Fibra Construções, 2004.

SILVA, F. A. I.. Infraestrutura Ferroviária e Desenvolvimento Econômico: o caso de um projeto de grande vulto.

Monografia (Graduação em Ciências Econômicas) Universidade Federal do Rio Grande do Sul, Porto Alegre, 2011.

WOMACK, J. P.; JONES, D. T.. Lean thinking: banish waste and create wealth in your corporation. New York: Free Press, 2003. 